\title{
Screening of Foot at Risk in Diabetic Patients
}

\author{
Djenebou Traore ${ }^{*}$, Djeneba Sylla Sow ${ }^{2}$, Massama Konaté2, Ousmane Sidibé2, \\ Modibo Mariko², Djibril Sy', Bah Traoré2, Karim Dao1, Amadou Koné2, Nanko Doumbia², \\ Nouhoum Ouologuem², Yacouba Lazard Diallo², Boua Daoud Camara1, Nongoba Sawadogo3, \\ Ibrahima Amadou Dembélé1, Barry Boubacar Sangaré1, Mamadou Cissoko1, \\ Mahamadou Saliou', Youssouf Fofana4, Mamadou Mallé1, Mamadou Togo², \\ Adramé Keita1, Abdramane Traoré5, Nagou Tolo5, Madani Ouologuem², \\ Abdel Kader Traoré1, Assa Traoré Sidibéz
}

${ }^{1}$ Department of Internal Medicine, The University Teaching Hospital of Point G, Bamako, Mali

${ }^{2}$ Department of Internal Medicine and Endocrinology, The Mali Hospital, Bamako, Mali

${ }^{3} \mathrm{CHR}$ Internal Medicine Department of Kaya, Kaya, Burkina Faso

${ }^{4}$ Department of Internal Medicine, The Mother and Children Hospital "Luxembourg”, Bamako, Mali

${ }^{5}$ Department Internal Medicine, The Hospital of Kati, Bamako, Mali

Email: *monopolytra@yahoo.fr

How to cite this paper: Traore, D., Sow, D.S., Konaté, M., Sidibé, O., Mariko, M., Sy, D., Traoré, B., Dao, K., Koné, A., Doumbia, N., Ouologuem, N., Diallo, Y.L., Camara, B.D., Sawadogo, N., Dembélé, I.A., Sangaré, B.B., Cissoko, M., Saliou, M., Fofana, Y., Mallé, M., Togo, M., Keita, A., Traoré, A., Tolo, N., Ouologuem, M., Traoré, A.K. and Sidibé, A.T. (2019) Screening of Foot at Risk in Diabetic Patients. Open Journal of Internal Medicine, 9, 62-71. https://doi.org/10.4236/ojim.2019.93009

Received: June 27, 2019

Accepted: August 31, 2019

Published: September 3, 2019

Copyright $\odot 2019$ by author(s) and Scientific Research Publishing Inc. This work is licensed under the Creative Commons Attribution International License (CC BY 4.0).

http://creativecommons.org/licenses/by/4.0/

\begin{abstract}
Introduction: The term "diabetic foot" refers to all conditions that affect the foot and are directly related to the impact of diabetes. Objective: Screen the foot at risk in diabetic patients at the hospital of Mali. Methods: It was a cross-sectional study from January $1^{\text {st }}, 2016$ to June 30, 2016, at the Department of Internal Medicine and endocrinology of the Hospital of Mali. It was focused on all hospitalized diabetic patients. Results: Thirty-two (32) patients had a foot at risk among 76 diabetic patients during the study period representing $42.10 \%$. The sex ratio was 0.52 . Type 2 diabetes accounted for $82 \%$. A glycemic imbalance (HBA1C $>7 \%$ ) was observed in $88.15 \%$. Eighteen percent (18\%) of patients had a history of ulceration or amputation; $33 \%$ were walking barefoot; $78.9 \%$ had tingles in the foot; $31.6 \%$ had intermittent claudication; $64.5 \%$ had foot cleanliness; $8 \%$ claw toes; $42 \%$ had abolition or reduction of superficial tenderness to monofilament and $21 \%$ had mixed foot (neuropathy + arteriopathy). In our study, $58.9 \%$ of patients had no risk of podiatry. Conclusion: Screening of foot at risk is essential in the management of diabetes because it determines the podiatric risk enabling to minimize future functional disabilities.
\end{abstract}

\section{Keywords}

Foot at Risk, Diabetes, Hospital of Mali

\section{Introduction}

The term "diabetic foot" refers to all conditions that affect the foot and are di- 
rectly related to the impact of diabetes. The foot of the diabetic patient is vulnerable and responsible for major functional disabilities, and impaired quality of life and death [1].

Management of diabetic foot requires a multidisciplinary approach. It is the leading cause of hospitalization of diabetic patients. The direct and indirect costs to society are considerable [2].

It is the largest provider of lower limb amputations in the world.

${ }^{*} 8 / 10$ non-traumatic amputations are due to diabetes.

*Amputation is made every 30 seconds in a diabetic patient in the world [3].

In Mali, the diabetic foot constitutes a major problem in our health structures both by the delay of the diagnosis and its care. In the Internal Medicine department of the University Hospital of Point G in Bamako, the diabetic foot problem represented $55 \%$ of hospitalization for diabetic patients, including $41 \%$ of amputations and $5.8 \%$ of deaths [4].

A study conducted at the University Teaching Hospital of Point-G noted that the total expenses for the management of extremities infection in diabetic patients was between 500.005 and $2.000 .000 \mathrm{~F}$ CFA in $51.5 \%$ of the cases [5].

Several studies have been conducted on the foot at risk due to neurological or vascular component or both. These two components are responsible for lesions or ulcerations of the foot with or without infection [6].

Given the seriousness of the problem, we conducted this study on diabetic feet at the Department of Internal Medicine and Endocrinology of the Hospital of Mali, a new structure of reference in diabetology.

\section{Objective}

Study the foot at risk among diabetic patients at the hospital of Mali.

\section{Methods}

The study was conducted at the Department of Medicine and Endocrinology of the Hospital of Mali. It was a prospective and descriptive study for the 6-month period (January 1 to June 30, 2016). It was focused on diabetic patients hospitalized during the study period.

Were included, all patients with diabetes who were hospitalized regardless of sex, age and the type of diabetes.

The data were collected on a pre-established individual questionnaire which was addressed to the patients regarding the objectives of the study. The questionnaire has been pretested and validated. Demographic data such as age, sex, profession as well as characteristics of diabetes including the type of diabetes, duration disease, and degenerative complications were collected.

Physical exam was performed to assess lower limbs arteriopathy highlighted by an ischemic necrosis of the extremities toes in the form of blackening of the toes, the perception or not of peripheral arterial pulses of the lower limbs (femoral, popliteal, pedis, posterior tibial pulse), cold extremities, and the search 
for an arterial murmur in the lower limbs.

Neuropathy for assessed highlighted by an edematous, a deformed, amyotrophy, the callus, hyperkeratosis, ulcerations of the lower limbs, and the Charcot's foot.

In addition to the abolition of tactile sensitivity to monofilament, the deep sensitivity to the tuning fork, and a reduction or abolition of osteo tendinous reflex were assessed.

Neuropathy was classified into:

Mild: the presence of functional signs and absence of physical signs.

Obvious: the presence of functional signs and physical signs.

Paraclinical exam included a recent report of fewer than 3 months of glycated hemoglobin [Good balance between 6.5\% - 7\% and balance $\mathrm{Bad}>7 \%$ ].

Patients were classified according to the podiatry risk of the ALFEDIAM classification that is shown in Table 1.

Data were entered on the software Excel 2007 and analyzed with SPSS Version 20.0 after cleaning. The statistical tests used were $\mathrm{chi}^{2}$ for the comparison of proportions (with $\mathrm{p}<0.05$ ).

All patients voluntarily accepted and provided verbal consent before inclusion in the study.

\section{Results}

During the study period; 76 cases of diabetes we recorded out of 321 patients hospitalized at the Department of Medicine and endocrinology of the hospital of Mali with a frequency of $23.67 \%$. Among them, 32 patients had a foot at risk which represented $42 \%$.

The limitations of the study were the lack of financial means to achieve a certain number of paraclinical results that were not used in the study to avoid missing data.

Women represented $66 \%(n=50)$ of the study population with a ratio of 0.52 shown in Figure 1.

Type 2 diabetes represented the majority of the studied population with $82 \%$ $(n=62)$.

Table 1. Podiatry risk according to the ALFEDIAM classification.

\begin{tabular}{cll}
\hline Grade & \multicolumn{1}{c}{ Definition } & \multicolumn{1}{c}{ Management } \\
\hline 0 & $\begin{array}{l}\text { Neuropathy, no arteritis, the possibility of } \\
\text { deformations nonspecific }\end{array}$ & Yearly exam of the feet \\
& $\begin{array}{l}\text { Neuropathy (monofilament not seen), } \\
\text { without arteritis nor deformations }\end{array}$ & $\begin{array}{l}\text { Exam of the feet and shoes at each } \\
\text { consultation. Patient education }\end{array}$ \\
& Neuropathy + arteritis and or deformation & $\begin{array}{l}\text { Same action + podiatry specialist } \\
\text { every two months + if necessary } \\
\text { orthosis and adapted shoes }\end{array}$ \\
& $\begin{array}{l}\text { History of amputation or ulcer with more } \\
\text { than } 3 \text { months duration }\end{array}$ & $\begin{array}{l}\text { Same action + education with a } \\
\text { specialized team }\end{array}$
\end{tabular}




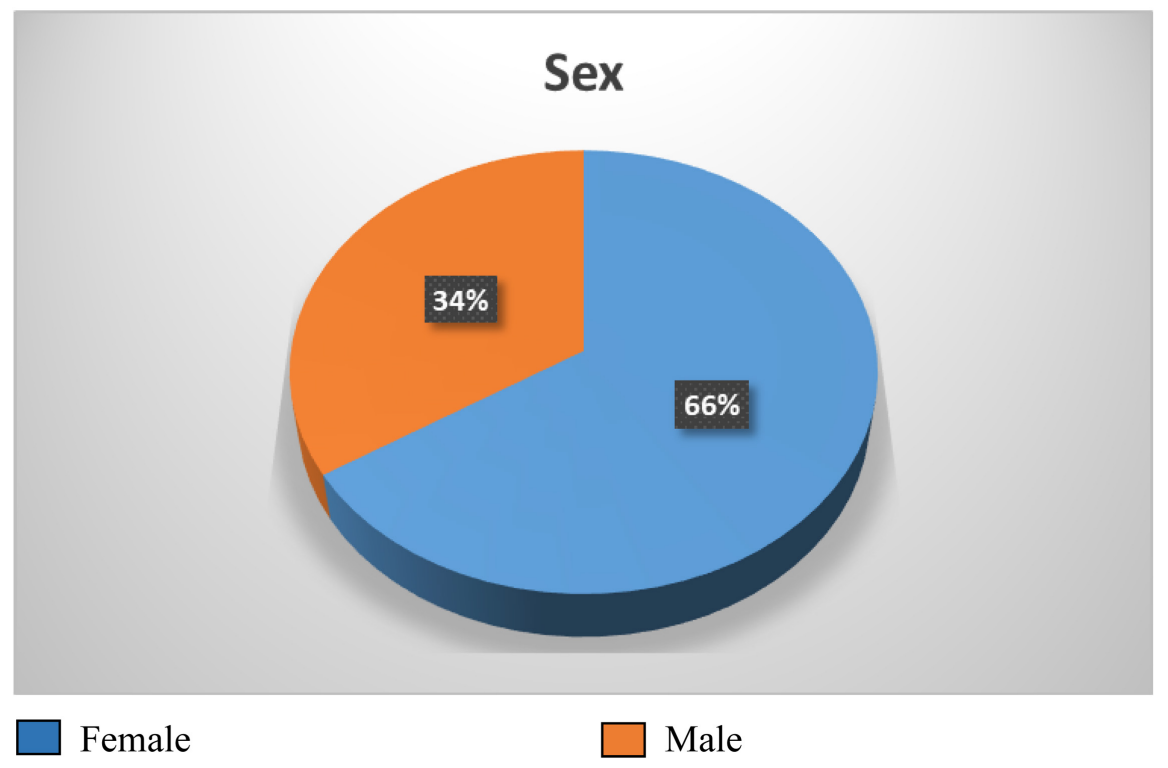

Figure 1. Distribution of patients by sex.

Patients with less than 5 years of diabetes progression represented $47.4 \%(\mathrm{n}=$ 36).

Eighteen percent (18\%) of patients had a history of ulceration ( $>3$ months) or amputation.

Almost all patients $(88.15 \%)(\mathrm{n}=70)$ were in glycemic imbalance (HBA1C > 7).

As a risk practice for patients shown in Table 2: Barefoot walking was found in $32.9 \%(\mathrm{n}=25)$; cutting nails at raw $25 \%(\mathrm{n}=19)$; using a sharpened instrument for horn $13.2 \%(\mathrm{n}=10)$; using corticoids $10.5 \%$; prolonged baths $22.5 \%$ $(\mathrm{n}=17)$.

According to the general aspects of the foot: More than half of the patients 64.5\% $(\mathrm{n}=49)$ had clean feet; $78.9 \%(\mathrm{n}=60)$ had tingling; $31.6 \%(\mathrm{n}=24)$ intermittent claudication; $14.4 \%(\mathrm{n}=11)$ had deformations of the foot (toe in claw or hammer teeth, hallux valgus and Quintus varus); $42.1 \%(\mathrm{n}=32)$ had abolition or reduction of superficial sensitivity to monofilament.

Less than half of the patients, $42 \%(\mathrm{n}=32)$ had diabetic neuropathy.

Lower extremity arteriopathy was present in $22.4 \%(\mathrm{n}=17)$ (of our patients, including $10.5 \%(\mathrm{n}=$ in stage II, $7.9 \%$ in stage III, $2.6 \%$ in stage I and $1.3 \%$ in stage IV) of the classification of Leriche and Fontaine.

Patients with a mixed foot (neuropathy + arteriopathy) represented $21.1 \%(\mathrm{n}=$ 16) of the study population.

The distribution shown in Figure 2 according to the podiatry risk of the classification of ALFEDIAM of the French society of diabetes (SFD) showed a grade 0 in $58 \%(\mathrm{n}=44)$, a grade 1 in $20 \%(\mathrm{n}=15)$, grade 2 in $14 \%(\mathrm{n}=11)$ and grade 3 in $8 \%(n=6)$.

The onset of Diabetic Foot Neuropathy increased with the duration of diabetes $(p=0.001)$, also for the arterial disease of the foot $(p=0.025)$. 
Table 2. Distribution according to risk practices.

\begin{tabular}{ccc}
\hline Practices at risk & Number of employees $(\mathrm{n}=76)$ & Percentage \\
\hline Barefoot & 25 & 32.9 \\
Cut raw nails & 19 & 25 \\
Use sharp instrument for horn & 10 & 13.2 \\
Use coricides & 8 & 10.5 \\
Extended baths & 17 & 22.5 \\
\hline
\end{tabular}

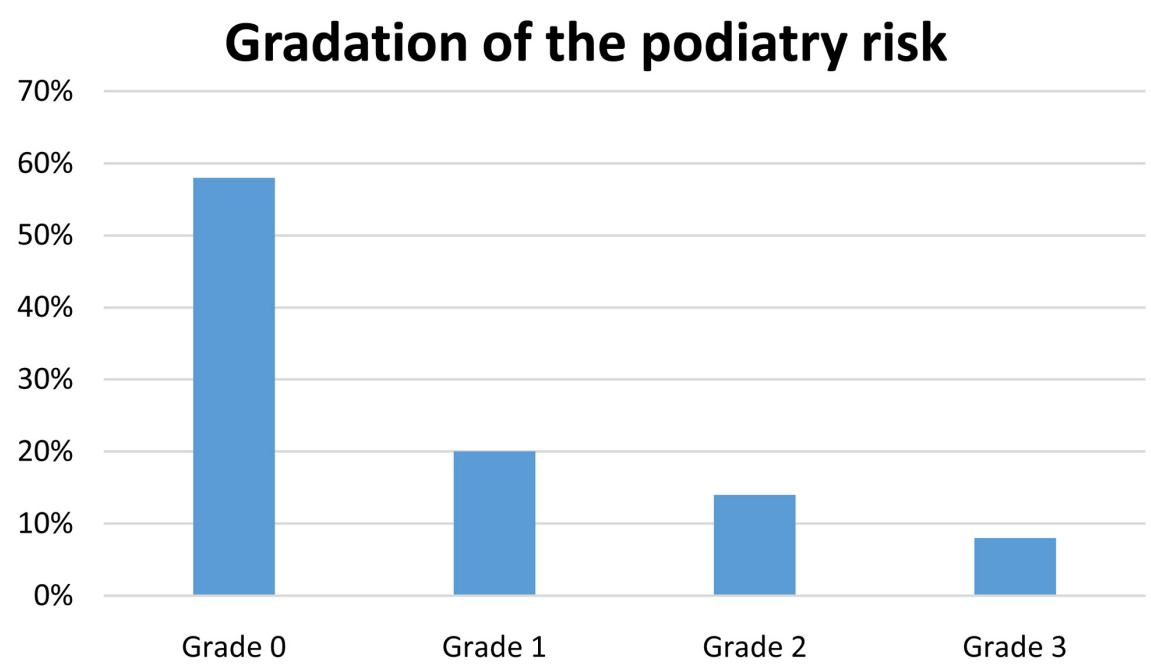

Figure 2. Patient distribution according to podiatry risk.

The risk of diabetic foot neuropathy increased with poor glycemic control $(\mathrm{p}=$ 0.045).

There was a statistically significant association between diabetic foot neuropathy and the history of ulceration or amputation $(\mathrm{p}=0.002)$.

Similarly, there was a statistically significant relationship between an arteriopathy foot and a history of ulceration or amputations $(\mathrm{p}=0.001)$.

\section{Comment and Discussion}

This was a prospective and descriptive study conducted at the Department of Medicine and Endocrinology of the Hospital of Mali from January 1, 2016, to June 30, 2016.

The study involved 76 diabetic patients out of a total of 321 patients hospitalized with a frequency of $23.67 \%$. This result is higher than that of TRAORE [7] who found $16.37 \%$. It is explained by the fact that; the department of endocrinology was newly opened at the hospital of Mali.

Of the 76 patients included in our study, $66 \%$ were women with a sex ratio of 0.52. This result is comparable to that of COULIBALY [8] who found a sex ratio of 0.55 .

Type 2 diabetes represented nearly all patients (82\%). This result is consistent with the literature data for type 2 diabetes which is and remains the most com- 
mon worldwide (80\% to $90 \%$ ) according to WHO [2]. This result is superimposable to those of TRAORE [9] and TRAORE [7] who found $96.1 \%$ and $91.5 \%$ respectively.

Nearly half of the patients (47.4\%) had recent-onset diabetes (an evolution period of fewer than 5 years). This result is lower than those of TRAORE [5] and CAMARA [10] who found $65.5 \%$ and $60.9 \%$ respectively. This could be explained by the massive screening for diabetes in recent years during the International Diabetes Day.

During our study, all our patients had performed the HbA1C test. Almost all of the patients had a poor balance with $88.15 \%$. This result is closer to those of TRAORE [7] and TRAORE [11] who found respectively $72.41 \%$ and $76 \%$. These poor results can be explained by the late diagnosis of diabetes [3].

Foot neuropathy was present in more than one-third of our patients with 42.1\%. This result is lower than that of TRAORE [9] and superior to CAMARA [10] results who reported respectively $55.6 \%$ and $28.8 \%$.

The onset of diabetic foot neuropathy increased with the duration of diabetes $(\mathrm{p}=0.001)$. This relationship was also found by TRAORE [9] and BARBOSA [12].

The risk of diabetic foot neuropathy increased with the poor glycemic control with a $(\mathrm{p}=0.045)$. This relationship was also found by TRAORE [9] and BARBOSA [12].

There was a statistically significant relationship between neuropathy of diabetic foot and a history of ulcers or amputations $(p=0.002)$. This result can be explained the existence already of neuropathy in the presence of ulcerations or amputations in the majority of cases [13].

The arteriopathy of the foot was present in quite more than a quarter of patients with $28.94 \%$. This frequency is higher than those of TRAORE [9] and KAGONE [14] who found respectively $15.1 \%$ and $11.8 \%$.

There was a statistically significant relationship between the duration of diabetes and the onset of foot arteriopathy $(p=0.025)$. This relationship was established in TRAORE's study [9] and KAGONE [14]. These results are explained by the physiopathology of diabetes for macroangiopathic complications that arise with the duration of diabetes [15].

There was a statistically significant relationship between the arteriopathy foot and history of ulcers $(3>$ months $)$ or with amputations $(\mathrm{p}=0.001)$. This result is explained by the longer time of ulcers for recovery in the presence of the foot arteriopathy, and the vast majority of diabetic patients are amputated for obliterate arteriopathy of the lower limbs [16].

About $2 / 3$ or $(57.9 \%)$ of the patients in our study were 0 podiatry risk. These results are lower than that of TRAORE [9] who found (70.3\%). These results can be explained by massive screening and early management of diabetes each year, especially during the International Diabetes Day enabling early management and a global education focused on the Foot. 


\section{Conclusion}

The screening of the foot at risk is essential in the management of diabetes because it can determine the podiatry risk leading minimize future functional disabilities.

\section{Conflicts of Interest}

The authors declare no conflicts of interest regarding the publication of this paper.

\section{References}

[1] Association of Diabetes and Metabolic Diseases (2010) The Feet of the Diabetic Patient. Endocrinology, 11, 5-16.

[2] WHO (2011) Report on the Global Situation of Non-Communicable Diseases in 2010. Executive Summary, 36, 1-20.

[3] Armstrong, D.G., Lipsky, B.A. and Singh, N. (2005) Preventing Foot Ulcers in Patients with Diabetes. JAMA, 293, 217-228. https://doi.org/10.1001/jama.293.2.217

[4] Sidibé, A.T., et al. (2006) Diabetic Foot in Internal Medicine of the Hospital of G Point. La Revue de Médecine Interne, 8, 14-17.

[5] Gory, B. (2009) Cost of Management of Extremity Infection in Diabetic Patients in the CHU Point-G Internal Medicine Department. Thesis, FMOS of Bamako, Bamako, 103

[6] Gumbach, M.L. and Richard, J.L. (2005) Foot Recommendation for Diabetics (ALFEDIAM 1996). 7th Edition, Cedex, Paris, 22-26.

[7] Traore, D., Sow, D.S., N’Djim, F., Konate, M., Doumbia, N.H., Mariko, M., et al. (2017) The Diabetic Foot in the Hospital of Mali. Medical B Burkina, 21, 212-226.

[8] Coulibaly, D.M. (2016) Arterial Hypertension in Diabetic Patients Followed in the Department of Medicine and Endocrinology of the Hospital of Mali. Thesis, FMOS of Bamako, Bamako, $136 \mathrm{p}$.

[9] Traore, D., Drago, A.A., Nientao, I.A., Sow, D.S., Menta, I. and Sidibé, A.T. (2014) Podiatric Risk in Diabetic Patients in a Bamako Referral Health Center. Medical Mali, 29, 14-18.

[10] Camara, A. (2010) Identification of Podiatric Risk in Diabetic Patients from Bamako in CHU Pont G, CHU Gabriel Touré, Diabetes Control Center, Reference Health Centers of Communes I and IV. Thesis, FMOS of Bamako, Bamako, 96 p.

[11] Traore, D.Y. (2013) The Prevalence of Diabetic Neuropathy in the Commune I of Bamako District. Thesis, FMOS of Bamako, Bamako, 107 p.

[12] Barbosa, A.P. (1999) Prevalence and Risk Factors of Clinical Diabetes Polyneuropathy in a Portuguese Primary Health Care Population. Diabetes and Metabolism, $25,35-42$.

[13] Prescribing-Writing (2001) Diabetes: Prevent Serious Lesions of the Feet. Prescribe Journal, 21, 204-213.

[14] Kagone, M. (1978) Diabetes Mellitus University Hospital of Lome. Study of 76 Cases. Diabetes Care, 8, 283-290.

[15] Duron, F. and Heurtier, A. (2006) Chronic Complications of Diabetes Mellitus. Endocrinology, 28, 267-280. 
[16] Armstrong, D.G., Harkless, L.B. and Lavery, L.A. (1998) Of a Diabetic Wound Classification System. Diabetes Care, 21, 855-859.

https://doi.org/10.2337/diacare.21.5.855 


\section{Investigation Sheet}

Name and surname: Age: BMI:

Type of diabetes Duration of diabetes progression

Gender: Profession:

\section{Followed:}

$\mathrm{HbA1C}=\%$

ATCD Ulceration or amputation: Yes: $\square$ No: $\square$

\section{Condition:}

Cracks: Yes: $\square$ No: $\square$

Cleanliness: Yes: $\square$ No: $\square$

Callosity: Yes: $\square$ No: $\square$

Infections: Yes: $\square$ No: $\square$

Neuropathic foot:

SF/Burns: Yes: $\square$ No: $\square$

Tingling: Yes: $\square$ No: $\square$

Cramps: Yes: $\square$ No: $\square$

Tingling: Yes: $\square$ No: $\square$

SP/ROT: Yes: $\square$ No: $\square$

Monofilament $=$ Sensitive: Yes: $\square$ No: $\square$

Diapason $=$ Sensitive: Yes $\square$ No $\square$

\section{Arteriopathic foot:}

SP: Cold feet

Yes: $\square$ No: $\square$

Cyanose in declivity: Yes: $\square$ No: $\square$

Thick nails: Yes: $\square$ No: $\square$

Intermittent claudication: Yes: $\square$ No: $\square$

Post Tibial Pulse Right: Yes: $\square$ No: $\square /$ Left: Yes: $\square$ No: $\square$

Pedal Pulse Right: Yes: $\square$ No: $\square /$ Left: Yes: $\square$ No: $\square$

\section{Deformities:}

Hallux valgus: Yes: $\square$ No: $\square$

Quintus varus: Yes: $\square$ No: $\square$

Toes in claw or hammer: Yes: $\square$ No: $\square$

Charcot's foot: Yes: $\square$ No: $\square$

Mixed foot: yes: $\square$ No: $\square$

\section{RISK Practices:}

Walk barefoot: Yes: $\square$ No: $\square$

Cut the fingernails: Yes: $\square$ No: $\square$

Use sharp instrument for horns: Yes: $\square$ No: $\square$

Use coricides: Yes: $\square$ No: $\square$

Extended baths: Yes: $\square$ No: $\square$ 


\section{Podiatric risk classification according to SFD (ALFEDIAM)}

\begin{tabular}{cl}
\hline Grade & \multicolumn{1}{c}{ Definition } \\
\hline 0 & Neither sensitive neuropathy nor arteritis \\
1 & Absence isolated from monofilament perception \\
& No perception of associated monofilament: \\
2 & $-\quad$ has arterial disease of the lower limbs and or \\
& Antecedent \\
3 & $-\quad$ dulcation of the foot evolving more than 4 weeks and or \\
\end{tabular}

